\title{
Language Matters -Representations of 'heart failure' in English discourse: a large-scale linguistic study
}

Jane Demmen $^{1 *}$, Nick Hartshorne-Evans ${ }^{2}$, Elena Semino ${ }^{1}$, Rajiv Sankaranarayanan ${ }^{3-5}$

${ }^{1}$ Lancaster University, ${ }^{2}$ The Pumping Marvellous Foundation, ${ }^{3}$ Liverpool University Hospitals NHS Foundation Trust, ${ }^{4}$ Liverpool Centre for Cardiovascular Science, University of Liverpool, ${ }^{5}$ National Institute for Health Research Clinical Research Network

\section{Authors}

\section{Dr Jane Demmen PhD}

Senior Research Associate

ESRC Centre for Corpus Approaches to Social Science,

Department of Linguistics and English Language,

County South, Lancaster University,

Lancaster LA1 4YL, UK

Email j.e.demmen1@1ancaster.ac.uk

2. Mr Nick Hartshorne-Evans (Heart Failure Patient, CEO and Founder of The Pumping Marvellous Charity - Registered Charity Number 1151848),

Suite 111 Business First Millennium City Park,

Millennium Road, Preston, PR25BL, UK

Email nick@pumpingmarvellous.org 


\section{Professor Elena Semino BA MA PhD FRSA, FAcSS}

Professor of Linguistics and Verbal Art

Director of the ESRC Centre for Corpus Approaches to Social Science.

Visiting Professor in the Faculty of Foreign Languages at Fuzhou University, China.

ESRC Centre for Corpus Approaches to Social Science,

Department of Linguistics and English Language,

County South, Lancaster University,

Lancaster LA1 4YL, UK

Email e.semino@lancaster.ac.uk

\section{Dr Rajiv Sankaranarayanan MBBS FRCP (Lon) FESC PhD}

Consultant Cardiologist and Heart Failure Lead

NIHR Research Scholar and Honorary Senior Lecturer

Liverpool University Hospitals NHS Foundation Trust,

Liverpool Centre for Cardiovascular Science, University of Liverpool

Liverpool, L97AL, UK

Email Rajiv.Sankaranarayanan@ liverpoolft.nhs.uk

Keywords Heart failure; discourse analysis; corpus linguistics

*Correspondence to: Jane Demmen, ESRC Centre for Corpus Approaches to Social Science, Department of Linguistics and English Language, County South, Lancaster University, Lancaster

LA1 4YL, UK. Email: j.e.demmen1@lancaster.ac.uk. 


\begin{abstract}
Aims

Heart failure (HF) has a lower public profile compared to other serious health conditions, notably cancer. This discourse analysis study investigates the extent to which HF is discussed in general contemporary English, UK parliamentary debates, and the ways in which HF is framed in discussions, when compared to two other serious health conditions, cancer and dementia.
\end{abstract}

\title{
Methods
}

The Oxford English Corpus of $21^{\text {st }}$ century English-language texts ( 2 billion words) and the UK Hansard Reports of parliamentary debates from 1945 to early 2021 were used to investigate the relative frequencies, contexts of use of the terms 'heart failure', 'cancer' and 'dementia'.

\section{Results}

In the Oxford English Corpus, the term 'heart failure' occurs 4.26 times per million words (pmw), 'dementia' occurs 3.68 times pmw and 'cancer' occurs 81.96 times pmw. Cancer is talked about 19 times more often than $\mathrm{HF}$ and 22 times more often than dementia. These are disproportionately high in relation to actual incidence: annual cancer incidence is 1.8 times that of the other conditions; annual cancer mortality is twice that caused by coronary heart disease (including heart failure) or dementia.

'Heart failure' is used much less than 'cancer' in UK parliamentary debates(House of Commons and House of Lords) between 1945 and early 2021, and less than 'dementia' from 1990 onwards. Moreover, HF is even mentioned much less than potholes in UK roads and pavements. In 2018, for example, 'pothole/s' were mentioned over 10 times pmw, 37 times more often than 'heart failure', mentioned 0.28 times pmw. Discussions of HF are comparatively technical and formulaic, lacking the survivor narratives that occur in discussions of cancer. 


\section{Conclusions}

HF is under-discussed in contemporary English compared to cancer and dementia. HF is also under-discussed in UK parliamentary debates, even compared to the less-obviously life threatening topic of potholes in roads and pavements.

What is already known on this topic - Heart failure is a serious health condition with significant morbidity and mortality, which is comparable to other serious health conditions such as cancer.

What this study adds - Our study has shown that heart failure is less frequently discussed in contemporary English as well as in UK parliamentary debates in comparison to other serious health conditions such as cancer and dementia, despite comparably significant adverse outcomes and also that discussions regarding people with heart failure are less empowering in comparison to discussions regarding cancer.

How this study might affect research, practice or policy? Results of this study should motivate all stakeholders involved in heart failure to redouble their efforts to spread awareness regarding the seriousness of the condition in general discourse as well as to engage parliamentarians better and thereby exert influence upon commissioners to significantly improve investment in prevention, early diagnosis and better management of heart failure. 


\section{Introduction}

Heart failure (HF) is a significant public health issue with an estimated global prevalence of sixty five million ${ }^{1}$, although the prevalence of known HF in the western world is around $1-2 \%{ }^{2}$. The prevalence of $\mathrm{HF}$ is predicted to increase significantly due to the ageing population, as well as improved survival from other medical conditions such as ischaemic heart disease, hypertension and disease $^{1}$. HF leads to high morbidity through poor health related quality of life $^{3}$ and recurrent hospitalisations with a 30 day readmission rate of around $20 \%{ }^{4}$. Heart failure also contributes to increased mortality (30 day, 1, 2, 5 and 10-year survival to be $10 \%, 20 \%, 27 \%, 43 \%$ and $65 \%$, respectively ${ }^{5-7}$. Heart failure consumes $1-2 \%$ of the annual healthcare budget in Europe and USA ${ }^{8,9}$ with the majority of costs (>70\% directed towards hospital care). Studies have shown that mortality due to HF is worse than certain types of cancer ${ }^{10,11}$. However, HF has not received a similar priority or profile such as other serious health conditions like as cancer in terms of government policy or funding and thus cancer has seen a much greater improvement in survival ${ }^{12,13}$. The improvement in cancer survival rates has been attributed to improvements in diagnosis and treatment due to better investment as well as changes in infrastructure since the introduction of the Cancer Plan in the UK two decades ago ${ }^{14}$

Large-scale discourse analysis using computer-assisted methods has been shown to be useful to understanding how people think and feel about serious health conditions, including cardiovascular disease and cancer ${ }^{15,16}$. There is little analysis to date of the way HF, specifically, is represented, apart from Strong and Gilmour's study of internet texts ${ }^{17}$. They noted that biomedical discourses (of a medical/technical nature, such as we found) were dominant, but also noted narratives of 'living with heart failure' which were scarce in our data. They noted an absence of talk about the contribution of nurses and the "emotional and spiritual dimensions of heart failure", which were also not noted in our data. We therefore conducted this study to investigate the extent to which HF is discussed in general contemporary English as well UK parliamentary debates, and in 
particular, compare reference to HF with discussions about other serious health conditions such as cancer and dementia. We also compare the frequency of references to HF in UK Parliamentary debates with references to a non-medical topic, namely, pot-holes on UK roads.

\section{Methods}

The study was commissioned by the Pumping Marvellous Foundation, a UK HF patient charity funded by donations and fundraising by individuals, with support from the NHS and charitable organisations plus corporate sponsorship. The study was conducted by linguists at the ESRC Centre for Corpus Approaches to Social Science, a research centre at Lancaster University which specialises in applying computer-assisted frequency-based statistical methods to the study of language in social life using large bodies of text.

Use of the terms 'heart failure' and 'cancer' was investigated in the following two data sets, or 'corpora':

- The Oxford English Corpus (OEC): 2,073,319,589 words of contemporary $\left(21^{\text {st }}\right.$ century) English from the UK, US, Ireland, Australia, New Zealand, the Caribbean, Canada, India, Singapore, and South Africa, compiled by Oxford Languages (Oxford University Press). Its contents are sourced mainly from web-based material supplemented by some printed texts and are grouped into the genres Medicine, News, Fiction, Life and leisure, Science, Society, Weblog, Arts, Sport, Business, Religion, Humanities, Law, Military, Computing, Agriculture, Environment, Paranormal, Transport, Games plus an Unclassified category. The OEC is accessible by subscription through SketchEngine ${ }^{18}$ (Lexical Computing), a webbased interface providing access to a range of corpora and corpus linguistics software tools (https://www.sketchengine.eu/).

- The Hansard Corpus (HC): Hansard reports of parliamentary debates in UK House of Commons \& Lords from 1 January 1945 up to and including 25 February 2021, accessed 
through Hansard at Huddersfield, a publicly-accessible interface and search tool provided by the University of Huddersfield (https://hansard.hud.ac.uk/site/site.php) $)^{19}$. More recent debates were accessed through the UK Parliament Hansard website (hansard.parliament.uk).

We refer to 'heart failure', 'cancer' and 'dementia' as linguistic terms when cited in single quotation marks, and as illnesses when not in quotation marks.

\section{Statistical analysis}

Simple frequency counts of occurrences of linguistic terms were carried out automatically by the software in the SketchEngine interface. SketchEngine also identified words which tend to cooccur most typically ('collocates') by computing LogDice ${ }^{20}$ scores measuring the strength of relationships between words and displaying these in rank order from most to least typical.

\section{Results}

Comparative frequency of use of the terms 'heart failure', 'cancer' and 'dementia' in contemporary English

Table 1 shows the actual (raw) frequencies of use for each term in the whole data set of contemporary English in the $\mathrm{OEC}(n)$ and the relative frequency per million words (pmw).

Across all geographical varieties of contemporary English the term 'heart failure' was mentioned much less often than the term 'cancer'. The greatest disparity was in Irish English, where 'cancer' was mentioned 111 times more often than 'heart failure', and the least disparity was in American English where 'cancer' was mentioned 14 times more often. In British English 'cancer' was mentioned 22 times more often than 'heart failure'. The comparison with 'dementia' was a little less consistent. 'Heart failure' was mentioned less often than 'dementia' in all varieties of English except for American English, where it was mentioned about twice as often, and East Asian 
English (about one and a half times more often). In British English the terms were mentioned with quite similar frequency ('heart failure' nearly 4.5 times pmw and 'dementia' just over 5 times pmw).

We compared figures indicating the relative incidence of the three diseases in the UK and in the world with the frequencies with which they are mentioned in the OEC. We also compared the annual incidence of these health conditions. Table 2 shows the number of new cases and annual deaths for each disease (note that these figures vary slightly according to different sources).[table 2] The number of new cases of heart failure and dementia in the UK are not dissimilar, at 200,000 and 209,600 respectively, as are the number of annual UK deaths caused by each disease $(64,000$ and 66,424 , respectively; heart failure is included with deaths from coronary heart disease in this figure and dementia is included with deaths from Alzheimer's Disease).

Table 3 shows the raw and relative frequencies of 'heart failure', 'cancer' and 'dementia' in different genres of contemporary English, according to the OEC text-type classifications (in descending order of raw frequency of 'heart failure').

Unsurprisingly the highest frequencies of all three terms were in the Medical genre, where they were used in biomedical senses in the discussion of medical research. 'Cancer' was mentioned about eight times more often than 'heart failure' in medical articles, and 'heart failure' was mentioned nearly twice as often as 'dementia'.

Outside of the Medical genre, the words most typically occurring with 'heart failure (the 'collocates') were other medical technical terms in biomedical contexts, revealing nothing of the person's experience of heart failure. For example, in the Life and leisure genre the collocates were 'congestive', 'CHF', 'hypertension' and 'kidney', and in the News genre 'congestive', 
'cardiomyopathy' and 'haemorrhage'. Apart from technical terms specifying some aspect of the illness, 'heart failure' was also typically associated with the word 'died' through the formulaic reporting of heart failure as the cause of death of a well-known person or public figure, as in ' $\mathrm{X}$ (has) died from/of heart failure'. Some examples are shown in the extracts from the corpus data in Table 4.

While other details of the person's life emerged in the wider context, the illness of HF itself was not usually discussed except in the context of the death having occurred. In the Life and leisure genre 'cancer' was often used in biomedical contexts, but also in contexts more oriented towards people's personal and emotional experience of the illness. The collocates of 'cancer' in the Life and leisure genre were mainly technical medical terms, as for 'heart failure', e.g. 'incidence' $(n=89)$, 'disease' (n=498), 'diabetes' ( $\mathrm{n}=104)$ and 'liver' (n=97). However, in contrast to 'heart failure', there were also two person-oriented collocates for 'cancer': 'survivors' (n=79) and 'battling' $(n=50)$, examples of which are shown in Table 5.

The 'survivor' narratives framed people with cancer as being relatively active and empowered. Through the use of violence metaphors 'battling' (lines 1 and 6) and 'beaten' (line 2), people with cancer were portrayed as actively aiming to live as long as possible, or recover. In line 1, people with cancer were framed as being able 'to voice their experience', another potentially empowering activity.

In the Life and leisure genre, there were some cases in which 'dementia' was discussed technically in biomedical contexts, shown in lines 1, 3, 4 and 8 in the examples in Table 6.

The collocates of 'dementia' in the Life and leisure genre were medical/technical terms ('senile', 'Vascular', 'Alzheimer' and 'colon'). There were examples of 'dementia' being used to 
frame people experiencing it in relatively empowering ways, as for 'cancer'. For instance, in line 5, Table 6, the writer mentioned bargaining, a process which framed the person with dementia as having some agency and power, although with or against whom was not clear from the wider context (perhaps medical professionals). In line 6 the writer used a violence metaphor to advise the reader to: "Defend yourself against dementia ...". In both scenarios a sense of opposition was created around the use of 'dementia', with the first writer indicating there is some sort of deal to be done and the second that the illness is an opposing force. There were no similar cases of such narratives for 'heart failure'.

Comparative frequency of use of the terms 'heart failure', 'cancer' and 'dementia' in parliamentary debates from 1945 to early 2021

Figure 1 shows the frequency of use 'heart failure', 'cancer' and 'dementia' in Hansard reports of UK House of Commons and House of Lords debates from 1 January 1945 (including the period leading up to the National Health Services Act of 1946 and the subsequent opening of the NHS in 1948) to 25 February 2021 (the latest date for which data was available).

The peak frequency of use of 'heart failure' in parliamentary debates was just under 1.0 pmw, in 2007.

Figure 1 shows that 'heart failure' was used with much lower frequency than 'cancer' across the whole time frame, and much lower frequency compared to 'dementia' from about 1990 onwards, so much so that the red line on the graph plotting instances of 'heart failure' is relatively invisible. Even when compared to a different, non-medical issue of arguably lower importance (in terms of potential threat to human life expectancy and quality of life), potholes in UK roads and pavements, 'heart failure' is discussed much less, as shown in Figure 2. 
As shown in Figure 2, the frequency of use of 'heart failure' was, for most of the period 1945 to 2021, lower than the frequency of talk about 'pothole/s', particularly over the last ten years when 'pothole/s' peaked in terms of frequency at:

- 10.24 times pmw in 2018 (about 37 times more often than 'heart failure' at 0.28 times pmw);

- 6.61 times pmw in 2014 (about 16 times more often than 'heart failure' at 0.42 times pmw); and

- 5.74 times pmw in 2010 (about 18 times more often than 'heart failure' at 0.32 times pmw). Occasionally prior to 2010 talk about 'heart failure' rose slightly above talk about 'pothole/s', most recently in 2007 when 'heart failure' peaked in use at 0.90 times pmw, about three times as often as 'pothole/s' (0.36 times pmw).

\section{Discussion}

The similar number of mentions of 'heart failure' and 'dementia' therefore roughly reflects a similarity in incidence of these diseases in term of numbers of new cases and annual deaths in the UK. The incidence of cancer is higher than that of heart failure and dementia, with about 1.8 times as many new cases of cancer being diagnosed every year compared to the other two diseases, and more than twice as many annual deaths are caused by cancer than by coronary heart disease (including heart failure) or dementia (including Alzheimer's Disease). The relative frequency of use of 'cancer' in the OEC data is therefore very much higher than the relative incidence of cancer compared to the other two diseases in the UK.

As shown in Table 2 similar numbers of cases of cancer and heart failure are diagnosed worldwide every year (17-18 million), but only about half as many cases of dementia (just under 10 million). The number of worldwide deaths from cancer and coronary heart disease (including heart failure) is also not dissimilar at 9-10 million, again much higher than the 1.5 million deaths from 
dementia. The relative frequency of use of 'cancer' in the OEC data is therefore again very much higher than the relative incidence of cancer compared to the other two diseases worldwide.

The above comparisons indicate, first of all, that cancer is talked about much more frequently relative to either heart failure or dementia and, secondly, that cancer is talked about with disproportionately high frequency relative to the incidence of the three diseases. O'Hanlon's 2019's corpus-assisted comparison of Twitter posts concerning breast cancer and heart disease similarly showed that there was much less talk about heart disease than breast cancer, although heart disease was responsible for many more annual deaths (in the US) than breast cancer ${ }^{15}$.

Violence metaphors, especially 'battle', 'struggle' and 'fight', regularly contribute to the construction of vivid scenarios in which people with cancer are relatively empowered. The framings of people with cancer as being 'survivors' who are 'battling' showed more of a person-centred focus, with vivid descriptors orienting the reader to the person's feelings as well as to their behaviours as a cancer sufferer. These contrasted with the formulaic uses of 'heart failure' as a cause of death, in which the person who suffers it was framed as a passive recipient. Even in more socially-oriented types of text, talk about HF is mainly of a biomedical nature, used in relatively technical and formulaic ways, especially in reporting cause of death. However, cancer is more typically mentioned in the context of incidence, diagnosis, cure or awareness - in many ways an opposite framing.

In contrast to $\mathrm{HF}$, cancer discussions regularly incorporate figurative language through which people with cancer are framed as 'survivors' actively 'battling' their illness. Empowering framings of people engaged actively in opposition to heart failure do exist, but these are very much less typical than in discussions of cancer. There is little evidence of person-centred discussion about the experience, feelings and/or emotions of people with HF or their quality of life. Our findings show some similarity to those of O'Hanlon 2019, who found that talk about heart disease, was less focused on personal experience than talk about breast cancer ${ }^{15}$. The importance of appropriate 
language has been emphasised recently, particularly in North America where there has been a trend to veer away from using the term 'failure' (due to the associated negative connotations) and instead to refer to "heart function' ${ }^{23}$. However this strategy can also risk a suggestion of appearing to minimise the severity of the condition as there is also evidence that some people with the condition can underestimate how sick they truly are ${ }^{24}$.

If we take frequency of mentions as an indicator of importance, topic of HF has been much less important in UK parliamentary debates in recent years than even potholes in roads and pavements. Whether this reflects the priorities of the parliamentarians, their constituents, or both, we cannot say from the information available. It is possible that more constituents contacted their elected representatives to complain about pot-holes than about provisions for the treatment and support of HF. We should note that, in addition to general frustration and inconvenience, pot-holes do pose some threat to health and quality of life (the AA reported in 2018 that 22 cyclists were killed and 368 seriously injured from accidents caused by potholes over a 12 -month period ${ }^{25}$ ). We might speculate that the amount of (negative) UK media coverage regarding pot-holes could be greater than that for HF, which may result in greater amounts of concern expressed in parliamentary debates.

It would be possible to investigate words most typically associated with 'heart failure' and 'cancer' on a statistical basis using the Wordsketch tool in SketchEngine, which identifies collocates according to grammatical function. This can be useful because words with different grammatical functions have particular roles. For instance, nouns are used for naming (e.g. cancer 'survivor/s'), and they function as subjects or objects (i.e. as social actors/agents who carry out actions or who are the recipients of actions). Verbs describe states, actions and processes, including what is being done or experienced (e.g. 'heart failure' typically occurs with verbs 'die' and 'suffer'). Investigating the grammatical characteristics of words typically occurring in the context of 
'heart failure' and 'cancer' could potentially reveal more details about the situations and framings in which the illnesses tend to occur.

It would also be possible and potentially useful to conduct a larger study using a wider range of cardiovascular terms (e.g. 'heart attack', 'cardiovascular disease', 'CHF') and to compare their frequency and manner of use with those for other health conditions apart from cancer, for example dementia/Alzheimer's Disease.

\section{Limitations}

It was outside the scope of this study to compare the frequency and manner of use of 'heart failure' and 'cancer' in different geographical varieties of contemporary English in detail (aside from noting overall trends in relative frequencies above). It was also not possible to discuss the use of 'heart failure', 'cancer' and 'dementia' in every genre of contemporary English, so we have reported on those showing the greatest contrasts.

A debate on 'Patients with Heart Failure' took place in the UK House of Commons on 11 March 2021, slightly later than the most recent debates currently accessible through the HC corpus interface, so it is not included in our data. The transcript is available at https://hansard.parliament.uk/Commons/2021-03-11/debates/14BCE210-9636-4060-8D0B31D9425BD334/PatientsWithHeartFailure?highlight=heart\%20failure\#contribution-98D83586DFF2-4926-A7A7-2B0FA62A831E.

\section{Conclusion}

Our study has elucidated that heart failure is relatively under-discussed in comparison to other conditions such as cancer and dementia, both in societal discourse as well as in UK parliamentary debates. Despite comparable morbidity and mortality, discussions regarding people with HF are less person-centred and empowering in comparison to the language used to describe 
people with cancer. In UK parliamentary debates, HF is also talked about less frequently than nonmedical topics such as pot-holes, which, although non-trivial, are arguably less important and urgent. It is crucial that all stakeholders involved in HF redouble their efforts to spread awareness regarding the seriousness of the condition and the pressing need to significantly improve investment in prevention, early diagnosis and better management.

\section{Ethics}

No data was collected and analysed involving human or animal participants for this study.

\section{Conflict of interest}

None declared.

\section{Funding}

Prof Semino's contribution was supported by the Economic and Social Research Council, part of UK Research and Innovation (grant reference no.: ES/R008906/1).

\section{Supporting information}

None.

\section{References}

${ }^{1}$ GBD 2017 Disease and Injury Incidence and Prevalence Collaborators. Global, regional, and national incidence, prevalence, and years lived with disability for 354 diseases and injuries for 195 countries and territories, 1990-2017: a systematic analysis for the Global Burden of Disease Study 2017. Lancet 2018; 392:1789-1858.

${ }^{2}$ McDonagh TA, Metra M, Adamo M, Gardner RS, Baumbach A, Böhm M, Burri H, Butler J, Čelutkienė J, Chioncel O, Cleland JGF, Coats AJS, Crespo-Leiro MG, Farmakis D, Gilard M, 
Heymans S, Hoes AW, Jaarsma T, Jankowska EA, Lainscak M, Lam CSP, Lyon AR, McMurray JJV, Mebazaa A, Mindham R, Muneretto C, Francesco Piepoli M, Price S, Rosano GMC, Ruschitzka F, Kathrine Skibelund A; ESC Scientific Document Group. 2021 ESC Guidelines for the diagnosis and treatment of acute and chronic heart failure. Eur Heart J 2021 Sep 21; 42(36):3599-3726.

${ }^{3}$ Johansson I, Joseph P, Balasubramanian K, McMurray JJV, Lund LH, Ezekowitz JA, Kamath D, Alhabib K, Bayes-Genis A, Budaj A, Dans ALL, Dzudie A, Probstfield JL, Fox KAA, Karaye KM, Makubi A, Fukakusa B, Teo K, Temizhan A, Wittlinger T, Maggioni AP, Lanas F, Lopez-Jaramillo P, Silva-Cardoso J, Sliwa K, Dokainish H, Grinvalds A, McCready T, Yusuf S; G-CHF

Investigators. Health-Related Quality of Life and Mortality in Heart Failure: The Global Congestive Heart Failure Study of 23000 Patients From 40 Countries. Circulation 2021 Jun; 143(22):21292142.

${ }^{4}$ Khan MS, Sreenivasan J, Lateef N, Abougergi MS, Greene SJ, Ahmad T, Anker SD, Fonarow GC, Butler J. Trends in 30- and 90-Day Readmission Rates for Heart Failure. Circ Heart Fail 2021 Apr; 14(4):e008335. doi: 10.1161/CIRCHEARTFAILURE.121.008335. Epub 2021 Apr 19.

${ }^{5}$ Jones NN, Roalfe AK, Adoki I, Hobbs FD, Taylor CJ. Survival of patients with chronic heart failure in the community: a systematic review and meta-analysis. Eur J Heart Fail 2019; 21:13061325.

${ }^{6}$ Gerber Y, Weston SA, Redfield MM, Chamberlain AM, Manemann SM, Jiang R, Killian JM, Roger VL. A contemporary appraisal of the heart failure epidemic in Olmsted County, Minnesota, 2000 to 2010. JAMA Intern Med 2015; 175:996-1004.

${ }^{7}$ National Heart Failure Audit 2019/20. National Institute for Cardiovascular Outcomes Research (NICOR), London. https://www.nicor.org.uk/heart-failure-heart-failure-audit/ (accessed 21 January 2022). 
${ }^{8}$ Liao L, Allen LA, Whellan DJ. Economic burden of heart failure in the elderly.

PharmacoEconomics 2008; 26(6):447-62.

${ }^{9}$ Braunschweig F, Cowie MR, Auricchio A. What are the costs of heart failure? Europace 2011 May; 13 Suppl 2:i13-7.

${ }^{10}$ Mamas MA, Sperrin M, Watson MC, Coutts A, Wilde K, Burton C, Kadam UT, Kwok CS, Clark AB, Murchie P, Buchan I, Hannaford PC, Myint PK. Do patients have worse outcomes in heart failure than in cancer? A primary care-based cohort study with 10-year follow-up in Scotland. Eur J Heart Fail 2017; 19:1095-1104.

${ }^{11}$ Stewart S, MacIntyre K, Hole DJ, Capewell S, McMurray JJ. More 'malignant' than cancer? Fiveyear survival following a first admission for heart failure. Eur J Heart Fail 2001 Jun; 3(3):315-22.

${ }^{12}$ Allemani C, Matsuda T, Di Carlo V, et al. CONCORD Working Group. Global surveillance of trends in cancer survival 2000-14 (CONCORD-3): analysis of individual records for $37 \square 513 \square 025$ patients diagnosed with one of 18 cancers from 322 population-based registries in 71 countries.

Lancet 2018; 391:1023-75.

${ }^{13}$ Taylor CJ, Ordóñez-Mena JM, Roalfe AK, Lay-Flurrie S, Jones NR, Marshall T, et al. Trends in survival after a diagnosis of heart failure in the United Kingdom 2000-2017: population based cohort study. BMJ 2019 Feb 13; 364:1223. doi: 10.1136/bmj.1223. PMID: 30760447.

${ }^{14}$ Exarchakou A, Rachet B, Belot A, Maringe C, Coleman MP. Impact of national cancer policies on cancer survival trends and socioeconomic inequalities in England, 1996-2013: population based study. BMJ 2018; 360:k764. doi: 10.1136/bmj.k764. PMID: 29540358.

${ }^{17}$ Strong AL, Gilmour JA. Representations of heart failure in Internet patient information. J Adv Nurs. 2009 Mar; 65(3):596-605.

${ }^{18}$ Kilgarriff A, Baisa V, Bušta J, et al. The Sketch Engine: ten years on. Lexicography 2014; 1:7-36.

${ }^{19}$ University of Huddersfield. Hansard at Huddersfield. https://hansard.hud.ac.uk/site/site.php (accessed 17 December 2021). 
${ }^{20}$ Rychlý P. A Lexicographer-Friendly Association Score. In: 2nd Workshop on Recent Advances in Slavonic Natural Languages Processing (RASLAN), Brno, Czech Republic, 2008: 2:6-9. Masaryk

University, Brno, Czech Republic. Published online

https://www.fi.muni.cz/usr/sojka/download/raslan2008/raslan08.pdf (accessed 17 December 2021).

${ }^{21}$ University of Huddersfield, UK. Hansard at Huddersfield (2021). "Heart failure, cancer and

dementia, 1945-2021” [Graph]. Available from: https://hansard.hud.ac.uk. (accessed 07.12.2021).

${ }^{22}$ University of Huddersfield, UK. Hansard at Huddersfield (2021). "Heart failure and pothole/s,

1945-2021" [Graph]. Available from: https://hansard.hud.ac.uk. (accessed 07.12.2021).

${ }^{23}$ Lala A, Mentz RJ. Contemplation from our hearts: a call to shift from failure to function. J Card

Fail 2021 Apr; 27(4):385. doi: 10.1016/j.cardfail.2021.03.002. PMID: 33745662.

${ }^{24}$ Ambardekar AV, Thibodeau JT, DeVore AD, Kittleson MM, Forde-McLean RC, Palardy M,

Mountis MM, Cadaret L, Teuteberg JJ, Pamboukian SV, Xie R, Stevenson LW, Stewart GC.

Discordant Perceptions of Prognosis and Treatment Options Between Physicians and Patients With

Advanced Heart Failure. JACC Heart Fail 2017 Sep; 5(9):663-671.

${ }^{25}$ Automobile Association (AA), UK. The shocking state of Britain's pavements.

https://www.theaa.com/about-us/newsroom/the-shocking-state-of-pavements (accessed 17

December 2021). 
medRxiv preprint doi: https://doi.org/10.1101/2022.02.10.22270750; this version posted February 13, 2022. The copyright holder for this preprint (which was not certified by peer review) is the author/funder, who has granted medRxiv a license to display the preprint in perpetuity.

It is made available under a CC-BY-ND 4.0 International license.

Table 1. Comparison of relative frequency of 'heart failure', 'cancer' and 'dementia' in contemporary English

\begin{tabular}{|l|l|l|l|l|l|}
\hline \multicolumn{2}{|l|}{ 'heart failure' } & \multicolumn{2}{l|}{ 'cancer' } & 'dementia' \\
\hline$n$ & pmw & $n$ & Pmw & $n$ & pmw \\
\hline 10,350 & 4.26 & 199,251 & 81.96 & 8,945 & 3.68 \\
\hline pmw = per million words & & & \\
\hline
\end{tabular}


Table 2. Incidence of heart failure, cancer and dementia in the UK and worldwide

\begin{tabular}{|c|c|c|c|c|}
\hline & \multicolumn{2}{|c|}{ New cases per year } & \multicolumn{2}{|c|}{ Deaths per year } \\
\hline & UK & Worldwide & UK & Worldwide \\
\hline $\begin{array}{l}\text { Heart } \\
\text { failure }\end{array}$ & $200,000^{1}$ & $17,900,000^{1}$ & $64,000 * 1$ & $9,100,000 * 1$ \\
\hline Cancer & $375,400^{1}$ & $17,000,000^{1}$ & $166,533^{1}$ & $9,600,000^{1}$ \\
\hline Dementia & $209,600^{1}$ & $9,900,000^{1}$ & $66,424 * * 1$ & $1,500,000 * * * 1$ \\
\hline \multicolumn{5}{|c|}{$\begin{array}{l}\text { *Coronary heart disease (rather than heart failure specifically) } \\
* * \text { Includes deaths from dementia and Alzheimer's Disease } \\
* * * \text { Estimated }\end{array}$} \\
\hline
\end{tabular}


Table 3. Comparison of relative frequency of 'heart failure', 'cancer' and 'dementia' in different genres of contemporary English

\begin{tabular}{|c|c|c|c|c|c|c|}
\hline \multirow[t]{2}{*}{ Genre (text-type) } & \multicolumn{2}{|c|}{ 'heart failure' } & \multicolumn{2}{|c|}{ 'cancer' } & \multicolumn{2}{|c|}{ 'dementia' } \\
\hline & $n$ & pmw & $n$ & pmw & $n$ & pmw \\
\hline Medicine & 7,646 & 102.08 & 62,075 & 828.74 & 3,891 & 51.95 \\
\hline News & 948 & 1.39 & 65,358 & 95.72 & 2,243 & 3.29 \\
\hline Unclassified & 433 & 1.25 & 16,563 & 47.69 & 781 & 2.25 \\
\hline Fiction & 345 & 4.56 & 1,338 & 17.67 & 62 & 0.82 \\
\hline Life and leisure & 194 & 1.44 & 13,938 & 103.53 & 364 & 2.70 \\
\hline Science & 193 & 1.70 & 10,413 & 91.80 & 283 & 2.49 \\
\hline Society & 124 & 1.04 & 5,473 & 45.99 & 160 & 1.34 \\
\hline Weblog & 115 & 0.53 & 7,057 & 32.74 & 318 & 1.48 \\
\hline Arts & 96 & 0.59 & 3,262 & 20.11 & 297 & 1.83 \\
\hline Sport & 83 & 0.79 & 2,474 & 23.62 & 35 & 0.33 \\
\hline Business & 67 & 0.66 & 3,346 & 33.01 & 59 & 0.58 \\
\hline Religion & 19 & 0.43 & 1,843 & 42.10 & 200 & 4.57 \\
\hline Humanities & 21 & 0.43 & 796 & 16.16 & 116 & 2.35 \\
\hline Law & 16 & 0.27 & 524 & 8.72 & 61 & 1.02 \\
\hline Military & 13 & 0.51 & 528 & 20.90 & 1 & 0.04 \\
\hline Computing & 13 & 0.16 & 1,179 & 14.67 & 31 & 0.39 \\
\hline Agriculture & 11 & 0.95 & 677 & 58.60 & 7 & 0.61 \\
\hline Environment & 7 & 0.78 & 1,741 & 194.78 & 18 & 2.01 \\
\hline Paranormal & 4 & 0.68 & 596 & 101.44 & 8 & 1.36 \\
\hline Transport & 2 & 0.19 & 59 & 5.61 & 0 & 0 \\
\hline Games & 0 & 0 & 11 & 2.93 & 10 & 2.66 \\
\hline
\end{tabular}


medRxiv preprint doi: https://doi.org/10.1101/2022.02.10.22270750; this version posted February 13, 2022. The copyright holder for this preprint (which was not certified by peer review) is the author/funder, who has granted medRxiv a license to display the preprint in perpetuity.

It is made available under a CC-BY-ND 4.0 International license.

Table 4. Examples of 'heart failure' in OEC Life and leisure genre used to discuss cause of death

\begin{tabular}{|l|l|}
\hline No. & Extract from data \\
\hline 1 & it could result in a sudden drop in blood pressure that could lead to heart failure. \\
\hline 2 & Gloria Hemingway, who died of heart failure in a private cell after being arrested for indecent exposure. \\
\hline 3 & When Francesco Scavullo died of heart failure on January 6 at 82, he was minutes away from a photo shoot \\
\hline 4 & founder of the National Lesbian and Gay Journalists Association, dies of heart failure in California \\
\hline 5 & Taylor suffers constant pain as a result of a bone disease and a congestive heart failure \\
\hline 6 & The 'Superman' star passed away from heart failure after being paralysed since falling from a horse \\
\hline
\end{tabular}


Table 5. Examples of 'survivors' and 'battling' associated with 'cancer' in contemporary English life and leisure genre

\begin{tabular}{|l|l|}
\hline No. & Extract from data \\
\hline 1 & But for the cancer survivors, it was the right day to voice their experience of battling the disease. \\
\hline 2 & welcomed him to the club of cancer survivors, people who've lived with it and who've beaten it. \\
\hline 3 & I've been able to talk to so many cancer survivors. \\
\hline 4 & I'm one of four brothers who are prostate cancer survivors. \\
\hline 5 & They are sleepovers with cancer survivors, under privileged children. \\
\hline 6 & kids come from all over to the Imus ranch. Some are cancer survivors, some are still battling cancer. \\
\hline
\end{tabular}


medRxiv preprint doi: https://doi.org/10.1101/2022.02.10.22270750; this version posted February 13, 2022. The copyright holder for this preprint (which was not certified by peer review) is the author/funder, who has granted medRxiv a license to display the preprint in perpetuity. It is made available under a CC-BY-ND 4.0 International license .

Table 6. Examples of 'dementia' in contemporary English life and leisure genre

\begin{tabular}{|l|l|}
\hline No. & Extract from data \\
\hline 1 & diseases and which untreated can lead to madness and finally to dementia? Another rhetorically powerful critic \\
\hline 2 & endow you with a longer shelf life by guarding against cancer, diabetes, dementia and getting knocked down by \\
\hline 3 & "Aluminum has been linked to Alzheimer's and dementia" (not to mention cancer and mad cow disease), claim \\
\hline 4 & but I can tell you that Alzheimer's is the leading form of dementia. And so, whatever the doctors - unless they \\
\hline 5 & You tend to bargain a bit when faced with the prospects of long-term dementia, but, frankly, from their \\
\hline 6 & some excellent ideas concerning the care of people suffering from dementia. We have had pupil-centred \\
\hline 7 & Use it or lose it Defend yourself against dementia by giving the brain a workout. While learning a language \\
\hline 8 & proteins in the brain) and Fronto-temporal dementia (associated with changes in the frontal lobe of the brain). \\
\hline
\end{tabular}


Figure 1. Examples of 'heart failure' in OEC Life and leisure genre used to discuss cause of death could result in a sudden drop in blood pressure that could lead to heart failure . $\langle/ \mathrm{s}\rangle\langle\mathrm{s}\rangle$ Likewise, mixing a vasoconstrictor with a vasodilator ca Ige didn't clear up everything for Gloria Hemingway, who died of heart failure in a private cell after being arrested for indecent exposure $</ s><\varsigma$ mething ) " - Lisa Neff $</ s><s>$ When Francesco Scavullo died of heart failure on January 6 at 82 , he was minutes away from a photo shoot of $C$ of the National Lesbian and Gay Journalists Association, dies of heart failure in California after a long battle with cancer . $</ \mathrm{S}><\mathrm{S}>\mathrm{The}$ U.S. Sur 'ers constant pain as a result of a bone disease and a congestive heart failure which makes breathing difficult. $</ \mathrm{S}><\mathrm{S}>$ " People must think, ' M! ;ities ". $</ s><s>$ ' Superman ' star Christopher passed away from heart failure last October Since his death, Dana - who has a 12 - year-old son 
Figure 2. Examples of 'survivors' and 'battling' associated with 'cancer' in contemporary English life and leisure genre

n the stereotype movie of audience 's delight. $</ \mathrm{s}\rangle\langle\mathrm{s}\rangle$ But for the

cancer survivors, it was the right day to voice their experience of battling the disease

Icomed Mr. Giuliani, not happily, but welcomed him to the club of

1. $</ s><s>$ And he has because I 've been able to talk to so many

vening, Larry . $\langle/ \mathrm{S}\rangle\langle\mathrm{S}\rangle \mid \mathrm{I}$ 'm one of four brothers who are prostate

e same bed as these children. $\langle/ \mathrm{s}\rangle\langle\mathrm{s}\rangle$ They are sleepovers with

cancer survivors, people who 've lived with it and who 've beaten it. $\langle/ s\rangle\langle s\rangle$ I 've jus'

cancer survivors. $\langle/ s\rangle\langle s\rangle \mid$ 've been able to talk to so many people into going and ha

cancer survivors. $\langle/ \mathrm{s}\rangle\langle\mathrm{s}\rangle$ I had a question for Tammy Faye 's brother - or husband

$\therefore, "$ kids come from all over to the Imus ranch.$\langle/ \mathrm{S}\rangle\langle\mathrm{S}\rangle$ Some are

cancer survivors, under privileged children . $\langle/ s\rangle\langle s\rangle$ When we come back, I 'll reintre

cancer survivors, some are still battling cancer. $\langle/ s\rangle\langle s\rangle$ Some have life-threatening 


\section{Figure 3. Examples of 'dementia' in contemporary English life and leisure genre}

ndocrine diseases and which untreated can lead to madness and finally to / endow you with a longer shelf life by guarding against cancer, diabetes zvision cameras . $\langle/ \mathrm{s}\rangle\langle\mathrm{s}\rangle$ " Aluminum has been linked to Alzheimer 's and :rson to answer it , but I can tell you that Alzheimer's is the leading form of $><s>$ You tend to bargain a bit when faced with the prospects of long-term tho has some excellent ideas concerning the care of people suffering from Ine system. $\langle/ \mathrm{s}\rangle\langle\mathrm{S}\rangle 17,\langle/ \mathrm{s}\rangle\langle\mathrm{S}\rangle$ Use it or lose it Defend yourself against ated with abnormal collection of proteins in the brain ) and Fronto-temporal dementia

dementia

dementia

dementia

dementia

dementia

dementia

dementia
? $</$ S $><$ S $>$ A nother rhetorically powerful critic of psychiatry , $\varepsilon$ and getting knocked down by a lorry . $\langle/ \mathrm{s}\rangle\langle s\rangle$ Not sure abou " ( not to mention cancer and mad cow disease), claim the $n$ $\langle/$ s $\rangle\langle$ s $\rangle$ And so, whatever the doctors - unless they did an ; but, frankly, from their perspective I probably looked like I v $</$ s $\rangle\langle$ s $\rangle$ We have had pupil-centred education for years, so by giving the brain a workout. $\langle/ \mathrm{s}\rangle\langle\mathrm{s}\rangle$ While learning a langi (associated with changes in the frontal lobe of the brain).$<$ 
$01.01 .1945-25.02 .2021$

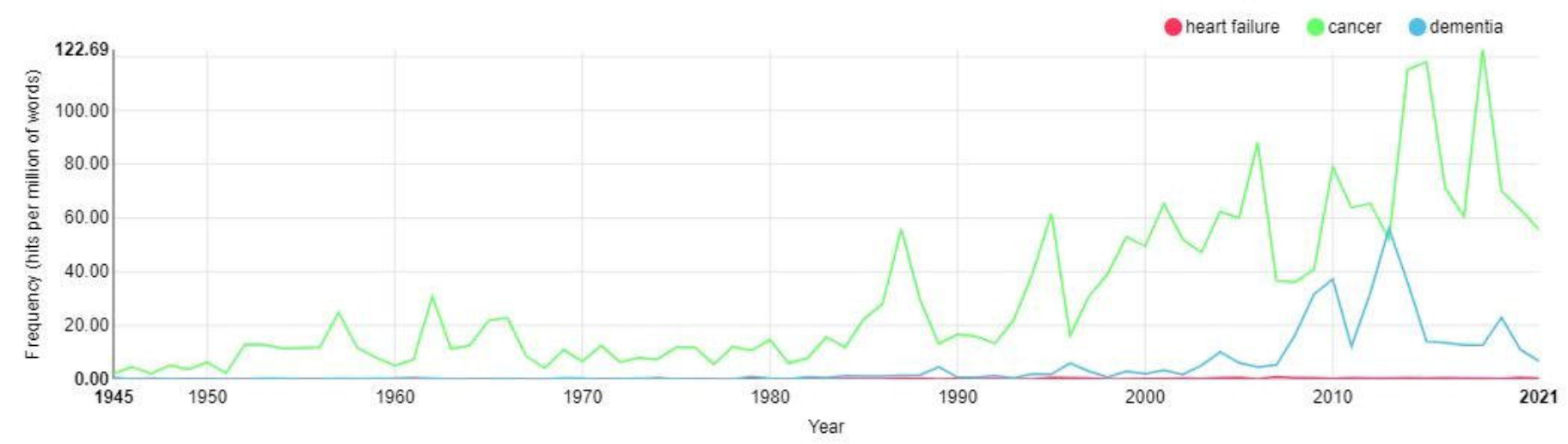

\section{Figure 4. Distribution of 'heart failure', 'cancer' and 'dementia' in UK parliamentary debates}


Figure 5. Distribution of 'heart failure' compared to 'pothole/s' in UK parliamentary debates $01.01 .1945-25.02 .2021$

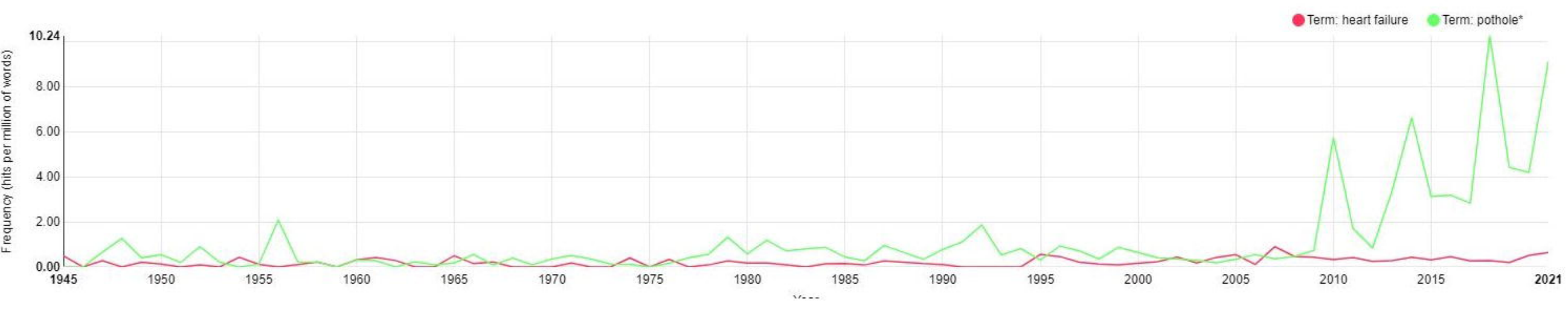

